\title{
INFORME SOBRE RESTABLECIMIENTO DE LA PENA DE MUERTE POR PROYECTO DE LEY (BOLETIN N 6642-07)
}

\author{
Humberto Nogueira Alcalá*
}

La Comisión de Constitución; Legislación y Justicia de la Cámara de Diputados me ha solicitado informe sobre la moción presentada que modifica el Código Penal y restituye en casos calificados la pena de muerte (Boletín $N^{\circ}$ 6642-07).

De acuerdo con el proyecto de ley planteado, se restablece la pena de muerte para delitos respecto de los cuales dicha pena ha sido eliminada por la ley $\mathrm{N}^{\circ} 19.734$, por medio del proyecto de ley consignado en el Boletín $N^{\circ}$ 6642-07, que introduce modificaciones al Código penal, en sus artículos 59 y 82 a 85.

El proyecto tiene un fundamento y argumentos que serán objeto de análisis jurídico constitucional en el presente informe.

El fundamento del proyecto afirma correctamente que la pena de muerte no ha sido abolida en Chile, ella subsiste para delitos establecidos en el Código de Justicia Militar en tiempo de guerra y se mantiene la norma constitucional del artículo $19 \mathrm{~N}^{\circ} 1$, inciso $3^{\circ}$, la que posibilita establecer por ley de quórum calificado la pena de muerte.

\section{La delimitación y configuración del derecho a la vida en nuestro ordenamiento jurídico.}

La Convención Americana de Derechos Humanos (CADH) en su artículo 4, asegura el derecho a la vida de las personas y el derecho a la vida del que está por nacer, generalmente, desde la concepción. El derecho a la vida en sus atributos asegurados y garantizados en dicha Convención Internacional de Derechos Humanos que constituyen derechos esenciales

* Doctor en Derecho por la Universidad Católica de Lovaina la Nueva, Bélgica. Profesor Titular de Derecho Constitucional y Director del Centro de Estudios Constitucionales de Chile, de la Universidad de Talca. Presidente de la Asociación Chilena de Derecho Constitucional y Vicepresidente del Instituto Iberoamericano de Derecho Procesal Constitucional. Correo electrónico: nogueira@utalca.cl. 
enriquecen los atributos del derecho a la vida asegurados por el artículo 19 de la Constitución, en el caso en análisis, todo ello de acuerdo al principio básico de interpretación constitucional favor persona o pro homine y al principio de progresividad, de acuerdo a la jurisprudencia tanto de nuestro Tribunal Constitucional, como de la Corte Interamericana de Derechos Humanos.

Así los atributos del derecho a la vida asegurados por la Constitución como los contenidos en la Convención Americana sobre Derechos Humanos constituyen atributos que emanan de la dignidad humana y constituyen derechos esenciales, los cuales, de acuerdo a lo que determina imperativamente el artículo $5^{\circ}$ inciso $2^{\circ}$ de la Constitución, limitan el ejercicio de la soberanía, por tanto, la potestad legislativa ejercida por los órganos colegisladores del Estado Chileno. Por tanto una disposición legal que actuara en tales términos sería inconstitucional, además de vulnerar un derecho humano esencial en los términos que el Estado de Chile, libre y voluntariamente se ha comprometido a respetar y promover, como dispone el mismo inciso $2^{\circ}$ del artículo $5^{\circ}$ de la Constitución. Cabe señalar, por tanto, que dichos atributos constituyen parte del parámetro de control de constitucionalidad, como ya fue utilizada la Convención sobre Derechos del Niño por el Tribunal Constitucional en su sentencia sobre "responsabilidad penal adolescente" (Rol N 786-2007, de fecha trece de junio de 2007) y en el caso de la "Píldora del día después", se aplica el mismo artículo $4^{\circ}$ de la Convención Americana sobre Derechos Humanos (sentencia Rol N 740-07, de fecha 18 de abril de 2008).

El aseguramiento del derecho a la vida en nuestro ordenamiento jurídico ha integrado el contenido mínimo asegurado por el artículo $4^{\circ}$ de la CADH, cuyo párrafo $2^{\circ}$ asegura en su parte final que "No se extenderá la aplicación de la pena de muerte a delitos a los cuales no se la aplica actualmente".

Esta disposición junto con ser parte de la CADH y del derecho internacional, es parte de nuestro ordenamiento jurídico y de aplicación preferente respecto de los preceptos legales internos, debiendo ser interpretada y aplicada de acuerdo con el objeto y fin de protección de los derechos a que se obligó el Estado de Chile de buena fe al incorporar tal disposición de aseguramiento y garantía del derecho a la vida. Así, el artículo 4.2 de la CADH establece un límite definitivo a la pena de muerte para todos los delitos que actualmente no contempla nuestro ordenamiento jurídico, prohibiendo la extensión de su uso hacia el futuro. Sobre ello ya se pronunció y dictaminó la Corte Interamericana en su Opinión Consultiva 3/83 de 8 de septiembre de 1983.

El Derecho Internacional de los Derechos Humanos es fuente del Derecho Interno cuando contiene elementos que enriquecen al Derecho Interno, cuando agregan un "plus" al contenido normativo de los derechos fundamentales delimitados y configurados en el derecho interno y viceversa, el sistema nacional de derecho enriquece al derecho Internacional de derechos humanos, buscando siempre la integralidad maximizadora del sistema de derechos esenciales 
o humanos, todo lo que está reconocido en el artículo 29 de la Convención Americana de Derecho Humanos y en el artículo $5^{\circ}$ del Pacto Internacional de Derechos Civiles y Políticos de Naciones Unidas.

El intérprete constitucional debe entender que existe una retroalimentación recíproca entre fuente interna y fuente internacional recepcionada internamente en materia de derechos fundamentales. En la misma perspectiva debe existir una retroalimentación entre el intérprete final del derecho interno y el intérprete final del derecho regional o internacional de derechos humanos, especialmente, de aquel que el Estado se ha comprometido a respetar y garantizar ante la comunidad internacional.

\section{La doctrina constitucional sobre la limitación del ejercicio de la soberanía por los derechos esenciales.}

Dicha perspectiva ha sido asumida también por don Alejandro Silva Bascuñan en su Tratado de Derecho Constitucional, donde afirma que el exacto alcance del artículo $5^{\circ}$, inciso segundo, oración final, es que "la obligación que impone al Estado tiene como ámbito todos esos derechos esenciales y, por lo tanto, no solo aquellos que explícitamente están reconocidos por la Ley Fundamental"1.

El profesor Silva Bascuñan concuerda con Cecilia Medina, además, en que "Si la comunidad internacional, o la nacional, se ponen de acuerdo en que ciertos derechos son 'humanos'o 'esenciales', ellos podrán ser invocados por sus titulares sin necesidad de verse expuestos a probar su naturaleza; ella ya está determinada de antemano y en forma fehaciente"2. Criterios que son reafirmados en el tomo XI del tratado, publicado en 2006, donde hace referencia a la materia en los párrafos 83 a 86 del Tomo IV³ .

El profesor Francisco Cumplido, ha señalado sobre la reforma constitucional de 1989 al artículo $5^{\circ}$, inciso $2^{\circ}$ :

"Para nosotros habría sido mucho mas técnicamente preciso incorporar a la Constitución todos los derechos humanos asegurados por tratados internacionales. Pero nos encontramos con que debíamos concordar la reforma

Silva Bascuñan, Alejandro. Tratado de derecho Constitucional. Tomo IV. Ed. Jurídica de Chile, Santiago, 1997, p. 111.

2 Silva Bascuñan, Alejandro. Tratado de Derecho Constitucional. Tomo IV. Ed. Jurídica de Chile, Santiago, 1997, p. 111.

Silva Bascuñan, Alejandro. Tratado de Derecho Constitucional. Tomo XI. Ed. Jurídica de Chile, Santiago, 2006, p. 15. 
en un tiempo muy breve. Por consiguiente, nos pusimos de acuerdo para que en la aprobación de esta reforma al artículo $5^{\circ}$, los derechos esenciales contenidos en los tratados internacionales ratificados por chile y vigentes, que conocía el constituyente - La junta de Gobierno en ese momento - y que conocían los negociadores, se entendiera que pasaban a formar parte de la Constitución Politica de 1980"4.

Así lo entiende también José Luis Cea Egaña, Ministro y ex Presidente del Tribunal Constitucional, en su obra Derecho Constitucional Chileno, donde afirma:

“En virtud del artículo $5^{\circ}$ inciso $2^{\circ}$, modificado en 1989, la Constitución hace parte formal y sustantiva de su texto los derechos, deberes, acciones y recursos contemplados en los tratados internacionales ratificados por Chile y vigentes en nuestro país que versen sobre los atributos esenciales de la persona humana. "Existe complementación, y no oposición, por ende, entre el Estatuto de la Persona en el derecho interno y en el derecho supranacional. Consecuentemente también, se ha vigorizado aquel estatuto por la conjugación o armonía de ambos sistemas jurídicos. Trátese de una evidencia más acerca de la nueva concepción de la soberanía, limitada y limitable por el respeto que debe al ejercicio de aquellos derechos" 5 .

De acuerdo a tal perspectiva, los derechos de fuente directamente constitucional, como asimismo, los derechos implícitos y los derechos de fuente internacional, constituyen un único bloque de derechos que se retroalimenta recíprocamente, en un sentido de progresividad y aplicando el principio favor persona, lo que posibilita que dimensiones o atributos de los derechos considerados inherentes a la persona o derivados de su dignidad humana que se encuentran asegurados por fuente internacional, sin derogar los derechos directamente constitucionales, pueden incorporarse como parte de ellos si aseguran o garantizan ámbitos de tales derechos que no estaban asegurados explícitamente por la norma constitucional.

Así este bloque de derechos esenciales, interpretados de acuerdo a las reglas y postulados de interpretación de los derechos humanos, constituyen parámetro de control de constitucionalidad de las normas internas infraconstitucionales. Así lo comprendió también el profesor Jaime Guzmán Errázuriz, el cual sostuvo en la Comisión de Estudios de la Nueva

$4 \quad$ Cumplido Cereceda, Francisco. "Los Tratados Internacionales y el artículo $5^{\circ}$ de la Constitución.", en Revista Ius et Praxis, Año $2 \mathrm{~N}^{\circ}$ 2, 1997, Facultad de Ciencias Jurídicas y Sociales, Universidad de Talca, Talca, Chile, pp. 95-96.

5 Cea Egaña, José Luis. Derecho constitucional chileno. Tomo I. Ed. Universidad Católica de Chile, Santiago, 2002. p. 113. 
Constitución que tales derechos posibilitaban el desarrollo de un recurso de inaplicabilidad por inconstitucionalidad.

\section{La jurisprudencia de la Corte Suprema y del Tribunal Constitucional sobre la materia.}

La Corte Suprema de Justicia afirma con claridad que la soberanía, incluido el poder constituyente y todo órgano o autoridad, está limitada por los derechos esenciales de la persona humana, a través de diversos fallos:

"Que en la historia fidedigna del establecimiento de la norma constitucional del artículo $5^{\circ}$ inciso segundo, queda claramente establecido que la soberanía interna del Estado de Chile reconoce como límite los derechos que emanan de la naturaleza humana; valores que son superiores a toda norma que puedan imponer las autoridades del Estado, incluido el propio Poder Constituyente, lo que impiden sean desconocidos (Fallos del Mes No 446, sección criminal, página 2066, considerando $4^{\circ}$ )"6 .

"Que, como lo ha señalado esta misma Corte Suprema en reiteradas sentencias, de la historia fidedigna del establecimiento de la norma fundamental contenida en el artículo $5^{\circ}$ de la Carta Fundamental, queda claramente establecido que la soberanía interna del Estado de Chile reconoce su límite en los derechos que emanan de la naturaleza humana, 'valores que son superiores a toda norma que puedan disponer las autoridades del Estado, incluido el propio poder constituyente, lo que impide sean desconocidos' (S.C.S. 30.1.2006)”? .

En la materia existe una larga lista de precedentes establecidos por la Corte Suprema de Justicia, entre ellos el siguiente:

"Trigésimonono: [...] En definitiva los derechos humanos asegurados en un tratado se incorporan al ordenamiento jurídico interno, formando parte de la Constitución material adquiriendo plena vigencia, validez y eficacia jurídica, no pudiendo ningún órgano del Estado desconocerlos y debiendo todos ellos respetarlos y promoverlos, como asimismo, protegerlos a través del conjunto de garantías constitucionales destinadas a asegurar el pleno respeto de los derechos. Esta obligación no sólo deriva del mentado artículo $5^{\circ}$, sino también del $1^{\circ}$, incisos primero y cuarto, y $19, N^{\circ} 26^{\circ}$, de la Carta Magna y de los mismos

$6 \quad$ Sentencia de la Corte Suprema, Rol No 469-98, de fecha 9 de septiembre de 1998, citado por Cea Egaña, José Luis. Derecho Constitucional Chileno. Tomo I, página 236.

Sentencia de la Corte Suprema, Rol N $559-04$, de fecha 13 de diciembre de 2006, considerando $22^{\circ}$. 
tratados internacionales, entre éstos del artículo $1^{\circ}$ común a los Cuatro Convenios de Ginebra, que establece el deber de los Estados Partes de respetar $y$ hacer respetar el derecho internacional humanitario.

Este carácter amplio de protección se desprende de la historia fidedigna del establecimiento del precepto aludido, puesto que su integrante Jaime Guzmán Errázuriz al recalcar que los derechos que arrancan de la naturaleza humana era "el único límite a la soberanía desde un ángulo objetivo, habida consideración que el debe proyectarse conceptualmente con la noción de bien común”, de tal suerte que aun cuando esos derechos no estén en el texto constitucional "no por eso una disposición jurídica cualquiera que atentara indebidamente en contra de ellos, dejaría de ser ilegítima" (Actas de la Comisión de Estudios de la Nueva Constitución, sesión 49 de veintisiete de junio de mil novecientos setenta y cuatro)" ${ }^{8}$.

En materia de otro derecho esencial, la Corte Suprema ha utilizado la misma línea argumental:

Décimo: Que, a lo anterior, y conforme la norma de reenvío contenida en el artículo $5^{\circ}$ de la Constitución, debe extenderse el reconocimiento con rango constitucional del derecho de defensa, también a los derechos garantizados por los tratados internacionales ratificados por Chile y que se encuentren vigentes como son los artículos 11.1 de la Declaración Universal de Derechos Humanos [...]; el artículo 14.3 del Pacto Internacional de Derechos Civiles y Políticos [...]; el artículo 8.2 de la Convención Americana de Derechos Humanos [...]"9.

Esta misma línea argumental ha sido desarrollada por nuestro Tribunal Constitucional, el cual precisa que:

“[...] el respeto y promoción de los derechos esenciales del hombre, que son superiores y anteriores al Estado y a la Constitución, que no los crea sino que reconoce y asegura", agregando que "estos preceptos no son meramente declarativos sino que constituyen disposiciones expresas que obligan a gobernantes y gobernados tanto en si mismas, como también, en cuanto normas rectoras y vitales que coadyuvan a desentrañar el verdadero sentido y espíritu

$8 \quad$ Sentencia de la Corte Suprema de Justicia, Sala Penal, Rol No 3125 - 04, de fecha 13 de marzo de 2007. Las negritas son nuestras.

9 Sentencia de la Corte Suprema de Justicia de 18 de abril de 2007 . Rol № 4.183 -06, considerandos noveno y décimo. Las negritas son nuestras. 
de las disposiciones de la Constitución” ${ }^{10}$.

Como el mismo Tribunal Constitucional ha explicitado:

$55^{\circ}$ [... " Como ha señalado el Comité de Derechos Humanos de la Organización de las Naciones Unidas, en su Observación General sobre el artículo $6^{\circ}$ del Pacto Internacional sobre Derechos Civiles y Políticos, el derecho a la vida es "el derecho supremo respecto del cual no se autoriza suspensión alguna, ni siquiera en situaciones que pongan en peligro la vida de la nación”. Ha agregado, asimismo, que "el derecho a la vida es el más esencial de estos derechos".

"56: Que el derecho a la vida asegurado por el artículo $19 N^{\circ} 1$ de la Constitución, en consonancia con el artículo $3^{\circ}$ de la Declaración Universal de los Derechos Humanos; el artículo 6.1 del Pacto Internacional de Derechos Civiles y Políticos; el artículo $1^{\circ}$ de la Declaración Americana de los Derechos y Deberes del Hombre, y el artículo $4^{\circ}$ de la Convención Americana de Derechos Humanos, asegura a toda persona -incluyendo al nasciturus- el derecho a mantener la vida y a conservarla frente a los demás hombres. Si se quiere, "es el derecho a que nadie nos la quite, y a que no pueda suprimirla ni cercenarla su propio sujeto" (José Joaquín Ugarte Godoy. El derecho a la vida y la Constitución. Revista Chilena de Derecho, Volumen 33, N³3, 2006, p. 514)."11.

\section{Obligación de adecuar el ordenamiento jurídico nacional al respeto y promoción de los derechos asegurados por la CADH.}

Cabe explicitar que el artículo $2^{\circ}$ de la Convención Americana sobre Derechos Humanos establece el deber del Estado Parte de adecuar su ordenamiento jurídico, a partir de la Constitución, y siguiendo por las leyes, a los derechos que se ha comprometido respetar de acuerdo al artículo $1^{\circ}$ de la misma Convención, derechos que como lo ha sostenido la jurisprudencia uniforme de la Corte Interamericana de Derechos Humanos, son de ejecución directa e inmediata, especialmente, en el caso del derecho a la vida.

\section{Reforma constitucional de 2005 en materia de tratados internacionales.}

Por otra parte, en el plano del derecho interno, debe explicitarse que, de acuerdo con la reforma constitucional de 2005, el artículo 54, en su inciso sexto del texto reformado introduce un principio de grandes repercusiones en el derecho interno y que es plenamente armónico con las obligaciones internacionales asumidas por el Estado Chileno en la Convención de Viena

Sentencia del Tribunal Constitucional, Rol N 943-07-INA, de 10 de junio de 2008, considerando $16^{\circ}$.

Sentencia del Tribunal Constitucional, Rol No 740-07, de fecha 18 de abril de 2008 , considerandos $55^{\circ}$ y $56^{\circ}$. 
sobre Derecho de los Tratados de 1969, ratificada en 1981 y publicada en junio de 1981. Dicho inciso precisa:

"Las disposiciones de un tratado sólo podrán ser derogadas, modificadas o suspendidas en la forma prevista en los propios tratados o de acuerdo a las normas generales de Derecho Internacional."

De acuerdo con esta disposición constitucional el Estado chileno no deja ninguna duda sobre la voluntad de hacer efectivas las obligaciones de ius cogens de cumplir de buena fe las obligaciones internacionales contenidas en los artículos 26 y 27 de la Convención de Viena sobre Derecho de los Tratados (principios Pacta Sunt Servanda y Bonna Fide), como asimismo la obligación de no oponer obstáculos de derecho interno al cumplimiento de las obligaciones internacionales voluntaria y libremente aceptadas, generando responsabilidad internacional por ello.

Una vez que el tratado internacional se encuentra aprobado por el Congreso Nacional y ratificado por el Presidente de la República, genera inmediatamente las obligaciones pertinentes para el Estado si tales tratados están vigentes en el derecho internacional, ellos pasan a ser derecho interno sin dejar de ser derecho internacional, pero, a diferencia de las normas generadas por fuente interna no son susceptibles de derogación por voluntad unilateral del Estado, teniendo aplicación preferente sobre el derecho interno de acuerdo a lo que el Estado ha consentido libre y voluntariamente. Dicha perspectiva fue expresamente asumida por el gobierno y los diversos sectores representados en el Senado en el primer trámite constitucional de la reforma constitucional de $2005^{12}$.

El Tribunal Constitucional en sentencia Rol No 288 de 24 de junio de 1999, respecto del requerimiento formulado respecto del Acuerdo entre Chile y Argentina sobre límites desde el monte Fitz Roy hasta el cerro Daudet, determinó que "el tratado y la ley son fuentes del derecho diferentes" (considerando $6^{\circ}$ ), asimismo ha afirmado que "después de la ratificación formal, el Estado se encuentra obligado a respetar sus cláusulas" (considerando $14^{\circ}$ ).

La Corte Suprema de Justicia, en fallo de fecha 26 de octubre de 1995, ha afirmado que la prescindencia de aplicación de normas de derechos humanos contenidas en tratados internacionales compromete la seguridad y honor del Estado de Chile y debilita el Estado de Derecho, no pudiendo invocarse el derecho interno para incumplir obligaciones internacionales:

"Que se comprometería la seguridad y honor del Estado de Chile ante la comunidad internacional, como se destaca en la sentencia recurrida, si este

12 Segundo Informe de la Comisión de Constitución, Legislación y Justicia del Senado, pp. 188 y siguientes. 
Tribunal efectivamente prescindiera de aplicar las normas internacionales cuando ello fuera procedente. Pues, es un principio reconocido universalmente que las naciones civilizadas no pueden invocar su derecho interno para eludir las obligaciones y compromisos internacionales asumidos por dichos tratados, lo que, ciertamente, de producirse debilitaría el Estado de Derecho"13.

A su vez, la desvinculación de Chile de un tratado internacional está específicamente señalado por la Constitución en el mismo artículo $44 \mathrm{~N}^{\circ} 1$, inciso $7^{\circ}$ :

"Corresponde al Presidente de la República la facultad exclusiva para denunciar un tratado o retirarse de él, para lo cual pedirá la opinión de ambas Cámaras del Congreso, en el caso de tratados que hayan sido aprobados por éste. Una vez que la denuncia o el retiro produzca sus efectos en conformidad a lo establecido en el tratado internacional, éste dejará de tener efecto en el orden jurídico chileno.”

En efecto, de acuerdo con esta disposición queda meridianamente claro que el Estado sólo puede desvincularse de cumplir sus obligaciones internacionales convertidas también en derecho interno obligatorio para todos los órganos estatales y los particulares a través de la denuncia del tratado en la medida que su propia naturaleza lo permita, y una vez cumplidas todas las etapas exigidas por el derecho internacional, sólo una vez que el derecho internacional y sus órganos jurisdiccionales de aplicación en su caso, determinen la liberación del Estado chileno de las obligaciones contenidas en el tratado, este podrá dejar de ser aplicado en el derecho interno.

\section{Conclusiones.}

El restablecimiento de la pena de muerte para determinados delitos por el proyecto de ley en análisis, respecto de los cuales se eliminó de nuestro ordenamiento jurídico dicha pena, implica violar los artículos 1, 2 y 4 de la CADH, con la consiguiente responsabilidad internacional, además de las decisiones jurisprudenciales vinculantes de la Corte Interamericana de Derechos Humanos, como asimismo, implicaría violar el contenido del derecho a la vida constitucionalmente garantizado por los artículos $19 \mathrm{n}^{\circ} 1 ; 5^{\circ}$ inciso $2^{\circ}$; y $19 \mathrm{~N}^{\circ} 26$, en armonía con el artículo $4^{\circ}$ de la CADH, lo que afectaría la constitucionalidad de tal disposición legal.

La única posibilidad de dar curso constitucional al proyecto de ley en análisis implica la previa denuncia de la Convención Americana sobre Derechos Humanos, esperando luego el

13 Sentencia de la Corte Suprema de Justicia, considerando $14^{\circ}$. 
curso de un año exigido desde el momento de la desvinculación, para poder concretar la tramitación válida y legítima del proyecto, todo ello sin perjuicio de las otras obligaciones internacionales aprobadas por el Estado de Chile referentes a la misma materia, entre ellas las convenciones sobre proscripción de la pena de muerte.

Es cuanto puedo informar a vuestra Comisión. 
Revista IUs et PraXis - AÑo 15 - № 2317 